\title{
Mobilita vybraných stopových prvků vázaných v hnědém uhlí mostecké pánve
}

\author{
Mobility of selected trace elements bound in brown coal of the Most basin
}

\author{
Marcela Cahová' $\square$, Eva Geršlová', Jan Kuta² \\ ' Ústav geologických věd PřF MU, Kotlářská 2, 61137 Brno \\ ${ }^{2}$ Centrum RECETOX PřF MU, Kamenice 5/753, 62500 Brno
}

\section{Key words:}

Most basin, Sequential Extraction Procedure, trace elements, brown coal

\section{凸436855@mail.muni.cz}

Editor:

Jiří Faimon

\begin{abstract}
Some of the trace elements bound in coal are potentially easily mobilizable and can represent a risk for an ecosystem. The aim of the study was to evaluate the extractability of selected metals from brown coal samples under surface conditions. Totally, 10 coal samples from the Main seam of Most Basin were studied using a sequential extraction procedure. Extraction conditions were set to represent real conditions on a dump. Extraction with deionized water was used for the most weakly bound and thus easily mobilizable elements, the amount of weakly adsorbed ions on the surface of the solid matrix was extracted with $1 M$ ammonium acetate solution at $\mathrm{pH}=7$. For the carbonate-bound fraction, respectively the fraction extractable under mildly acidic conditions, the same reagent at $\mathrm{pH}=5 \mathrm{was}$ used. Highest extractable contents in case of arsenic were found in deionized water for samples 03-07, other samples exhibited the highest recovery with weakly acidic reagent $(p H=5)$ with concentration $1 \mathrm{~mol} / \mathrm{l}$. Nickel concentrations in the extracts were mostly low (hundredths to tenths $\mu g / g$ ). Exceptions are water extractable contents (single units of $\mu \mathrm{g} / \mathrm{g})$ in samples 01,08 and 09. A positive correlation $(r=0.69)$ was found between the total content of As and Ni, however, the contents of As and Ni do not mutually correlate in each type of extract. Significant contents of vanadium (up to $0.844 \mu \mathrm{g} / \mathrm{g}$ ) and chromium (up to $0.28 \mu \mathrm{g} / \mathrm{g}$ ) were already extracted using deionized water. Very close behavior of chromium and vanadium was confirmed by positive correlation in mobile water extractable $(r=0.95)$ and carbonate fraction $(r=0.85)$.
\end{abstract}

\section{Úvod}

Anorganické prvky v uhlí pochází ze tři zdrojů. Prvním z nich je rostlinný materiál, který obsahuje stopové prvky vázané přímo na rostlinná pletiva. Obzvláště dřevo, hlavní stavební materiál kerogenu III, obsahuje často vyšší podíl stopových prvků. Řada rostlin obsahuje tzv. fytolity - mikroskopické inkrustace tvořené převážně oxidem křemičitým ve kterých bývají navázány také další stopové prvky (Taylor et al. 1998). Druhým významným zdrojem stopových prvků v uhlí jsou minerály uvolněné při zvětrávání hornin v okolí sedimentární pánve. Do této kategorie patří také vulkanický popel, který je význačným zdrojem vyšších obsahů stopových prvků jako je Se, V nebo Ni (Speight 2016; Swaine 1990). V průběhu diageneze dochází postupně ke vzniku uhelné polohy. Následné proudění nasycených roztoků v uhelných slojích, způsobuje postupné vysrážení nových minerálů. Podle podmínek v sedimentární pánvi může docházet k interakci mezi roztokem a funkčními skupinami uhelné hmoty. Ta vede k zabudování anorganické fáze př́imo do uhelné hmoty. Jedinečnost 
každé jednotlivé sedimentární pánve vede tedy zákonitě $\mathrm{k}$ vysoké variabilitě vazeb př́tomných prvků a velmi obtížnému stanovení množství přítomných anorganických složek, které se mohou uvolňovat do okolního prostředí (Dai et al. 2017; Finkelman 1995; Taylor et al. 1998). Tyto informace jsou ale pro hodnocení chování uhlí a uhelných jílovců klíčové (Suárez-Ruiz, Ward 2014). Celkové obsahy nemusí v řadě př́padů vypovídat o míře nebezpečnosti pro životní prostředí. Význam hodnocení míry pohyblivosti stopových prvků se zvyšuje v okamžiku aktivní těžby uhlí a tvorbě výsypek. Zde dochází ke vstupu kyslíku, zvětrávání a uvolnění prvků do prostředí (Sia, Abdullah 2011; Vejahati et al. 2010).

Uhlí a uhelné jílovce jsou tvořeny organickou hmotou, která představuje 70-100 obj. \% a anorganické prvky jsou přítomny v malém množství. Analytické stanovení obsahu prvků je metodicky náročnější než analýza organikou chudších materiálů. Obvyklý postup stanovení celkové koncentrace prvků $v$ uhlí vychází $z$ analýzy popela, kdy je třeba zohlednit tu skutečnost, že těkavé sloučeniny prvků mají tendenci se odpařit (Suárez-Ruiz, Ward 2014).

Sekvenční extrakční analýza (SEA) funguje na principu postupného uvolnění složek vázaných v matrici extrakčním činidlem do roztoku. Díky této metodě je možné simulovat reálné př́rodní podmínky a definovat tak skutečné množství prvku vstupující do prostředí (Ettler 2008; Vöröš et al. 2019). Tato informace je mnohem důležitější než absolutní koncentrace. Metoda byla poprvé navržena Tessierem et al. (1979) a využívána především pro analýzu půd a sedimentů vodních toků. V této práci byla SEA upravena podle Feng et al. (2000) a Querol et al. (1996) a využita pro stanovení mobility stopových prvků v hnědém uhlí Mostecké pánve.

Cílem práce bylo provést sekvenční extrakční analýzu pro hodnocení mobility stopových prvků v uhelné hmotě. Práce hodnotila prvky As, $\mathrm{Cr}, \mathrm{Ni}$ a V ve vzorcích hnědého uhlí mostecké pánve.

\section{Metodika}

V povrchovém lomu Bílina bylo odebráno 10 vzorků hnědého uhlí tak, aby reprezentovaly vertikální profil hlavní sloje. Odebrané vzorky byly vysušeny, podrceny, přesítovány na frakci $<63 \mu \mathrm{m}$ a následně homogenizovány. Základní technologické parametry a obsahy prvků extrahovatelné lučavkou královskou vzorků uhlí jsou převzaty z práce Fojtík (2018). Sekvenční extrakce vzorků byla provedena s jistou modifikací dle prací Querol et al. (1996) a Feng et al. (2000). Vzorky byly postupně extrahovány činidlem s rostoucí extrakční silou. Uvolněná frakce prvků je uvedena v závorce. 1) deionizovaná voda (mobilní frakce); 2) 1M roztok octanu amonného, pH 7 (výměnné frakce); 3) 1M roztok octanu amonného, $\mathrm{pH} 5$ (uhličitanové frakce, frakce rozpustné v slabě kyselém prostředí).

Roztoky octanu amonného byly připraveny z koncentrované kyseliny octové (čistota p.a., Merck) a upraveny na př́slušné $\mathrm{pH} 10 \%$ roztokem $\mathrm{NH}_{4} \mathrm{OH}$ (p.a, Merck). Extrahovány byly $2 \mathrm{~g}$ vzorku v $10 \mathrm{ml}$ příslušného extrakčního činidla po dobu 20 hodin na horizontální třepačce GFL 3006 rychlostí 150 min $^{-1}$. Po extrakci následovala centrifugace vzorků (centrifuga EBA Hettich 20), filtrace přes membránové filtry (PTFE, 0,45 $\mu \mathrm{m}$, VWR) a stabilizace vzorků přídavkem kyseliny dusičné (p.a., Merck, prídavek $0,05 \mathrm{ml}$ na $5 \mathrm{ml}$ extraktu). Koncentrace zájmových prvků v extraktech byla stanovena metodou hmotnostní spektrometrie s indukčně vázaným plazmatem (Agilent 7700x ICP-MS).

Statistická analýz dat byla provedena v softwaru Prism 6 (GraphPad Software, Inc.). Korelační analýza byla provedena na logaritmovaných datech, korelace je kvantifikována pomocí Personova korelačního koeficientu r.

\section{Výsledky}

Přestože bylo k dispozici 10 vzorků hnědého uhlí odebraného $\mathrm{z}$ hlavní sloje dolu Bílina, jedná se o poměrně heterogenní soubor jak z pohledu technologických vlastností, tak celkové koncentrace sledovaných prvků (obr. 1). Parametry popelovina a koncentrace celkové síry jsou obvykle využívány pro prvotní odhad potenciálního obsahu prvků v uhlí. U studovaných vzorků uhlí je široký rozsah popeloviny od 1,67-41,52 hm. \% a celková síra v intervalu $0,41-2,30 \mathrm{hm}$. \%. Detailní zhodnocení vzorků neprokázalo korelaci mezi absolutními koncentracemi stopových prvků a celkovou popelovinou a lze nepřímo usuzovat, že studované kovy jsou vázány na organickou hmotu (Fojtík et al. 2018; Vöröš et al. 2019). Vzorky obsahovaly nejvíce vanadu a nejméně arsenu (obr. 1).

Vzorky 01, 02, 03, 07, 08 a 10 mají srovnatelnou distribuci sledovaných prvků, jejich koncentrace postupně stoupá v pořadí arsen, chrom, nikl a vanad. Vzorky 04, 06 a 09 mají vyšší obsah chromu oproti niklu. Ze skupiny vzorků vybočuje vzorek 05, který má nejvyšší obsah niklu, obsah arsenu, chromu a vanadu je srovnatelný.

Analýza výluhů $\mathrm{z}$ jednotlivých kroků extrakce prokázala mobilizovatelné množství As ve vzorku 08

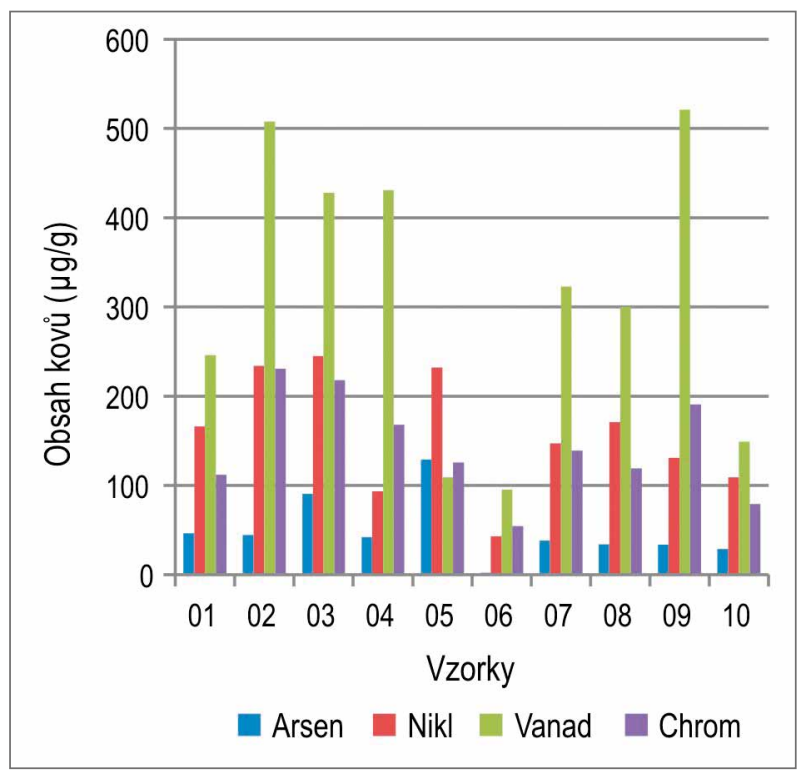

Obr. 1: Celkové množství sledovaných kovů ( $\mu \mathrm{g} / \mathrm{g}$ ) ve vzorcích hlavní sloje dolu Bílina.

Fig. 1: The content of evaluated metals $(\mu \mathrm{g} / \mathrm{g})$ in the brown coal of Bílina mine. 


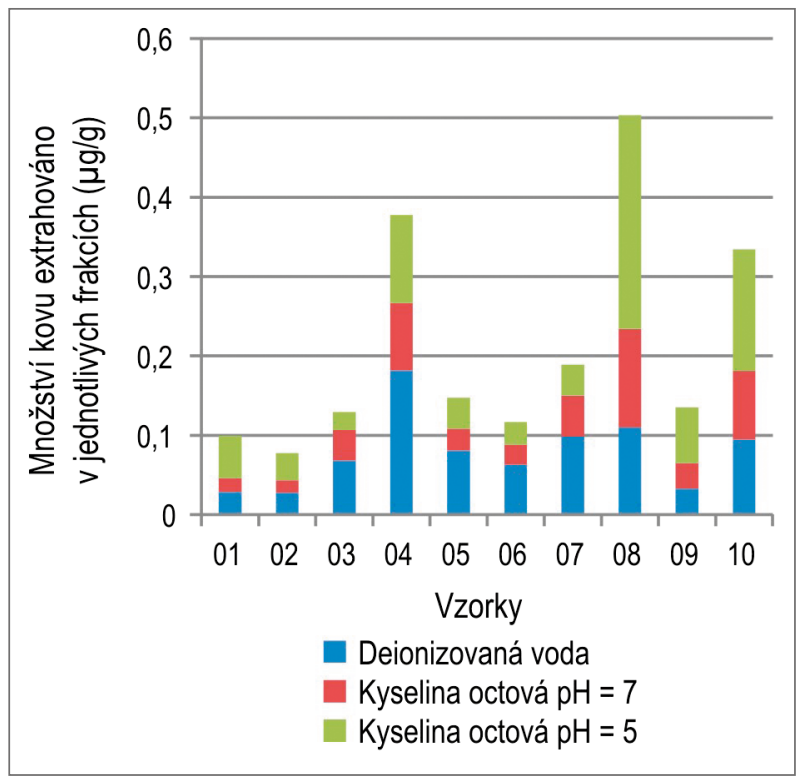

Obr. 2: Množství arsenu ( $\mu \mathrm{g} / \mathrm{g})$ stanovené ve výluzích s odlišnou hodnotou $\mathrm{pH}$.

Fig. 2: The content of arsenic $(\mu \mathrm{g} / \mathrm{g})$ determined in the extracts with a different $\mathrm{pH}$.

a nejméně ve vzorku 02 (obr. 2). U vzorků 01, 02, 08, 09 a 10 bylo nejvíce arsenu uvolněno $\mathrm{v}$ uhličitanové frakci, méně v mobilní fázi a nejméně arsenu bylo stanoveno ve výměnné frakci. $U$ vzorků $03,04,05,06$ a 07 bylo nejvyšší množství stanoveno ve výluzích $\mathrm{z}$ deionizované vody, méně při pH 7 a nejmenší množství kovu bylo detekováno $\mathrm{v}$ extraktech získaných při použití roztoku $\mathrm{pH}=5$.

$\mathrm{V}$ prípadě Ni bylo ve vzorcích 01,08 , pak 09 a 10 největší množství kovu extrahováno $\mathrm{v}$ prvním kroku extrakce za použití deionizované vody (obr. 3). $V$ těchto vzorcích lze také pozorovat, že množství detekovaných kovů ve výměnné frakci při použití kyseliny octové $(\mathrm{pH}=7)$ bylo nižší než v uhličitanové frakci $(\mathrm{pH}=5)$.

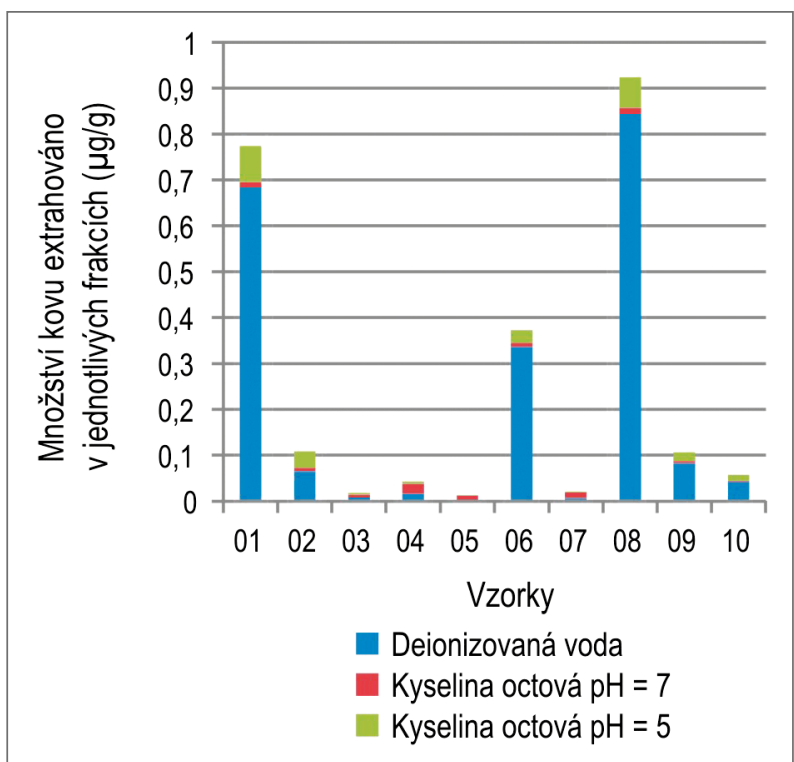

Obr. 3: Množství niklu ( $\mu \mathrm{g} / \mathrm{g})$ stanovené ve výluzích s odlišnou hodnotou $\mathrm{pH}$.

Fig. 3: The content of nickel $(\mu \mathrm{g} / \mathrm{g})$ determined in the extracts with a different $\mathrm{pH}$.

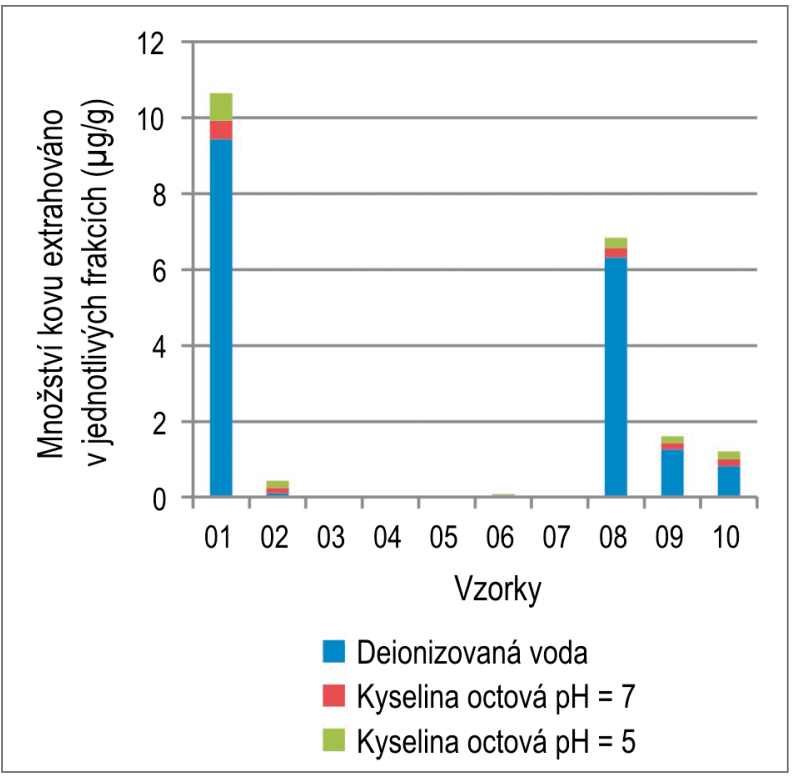

Obr. 4: Množství vanadu ( $\mu \mathrm{g} / \mathrm{g})$ stanovené ve výluzích s odlišnou hodnotou $\mathrm{pH}$.

Fig. 4: The content of vanadium $(\mu \mathrm{g} / \mathrm{g})$ determined in the extracts with a different $\mathrm{pH}$.

U vzorku 02 množství extrahovaného kovu stoupalo se silou extračního činidla. Absolutní koncentrace byly ovšem velice nízké. V ostatních vzorcích (03-07) bylo množství $\mathrm{Ni}$ ve všech krocích extrakce zanedbatelné př́ípadně pod mezí detekce metody.

U vzorků 01, 02, 06, 08, 09 a 10 bylo zjištěno nejvyšší množství vanadu ve výluhu z deionizované vody, menší množství $v$ uhličitanové frakci při $\mathrm{pH}=5$ a nejnižší koncentrace ve výměnné frakci př̀ $\mathrm{pH}=7$ (obr. 4). U vzorku 04 byla nejvy̌šší koncentrace zjištěna ve výměnné frakci.

$\mathrm{V}$ př́padě chromu se ve vzorcích $01,06,08,09$ a 10 extrahovalo nejvíce kovu deionizovanou vodou, menší množství bylo ve výměnné frakci a nejméně ve frakci

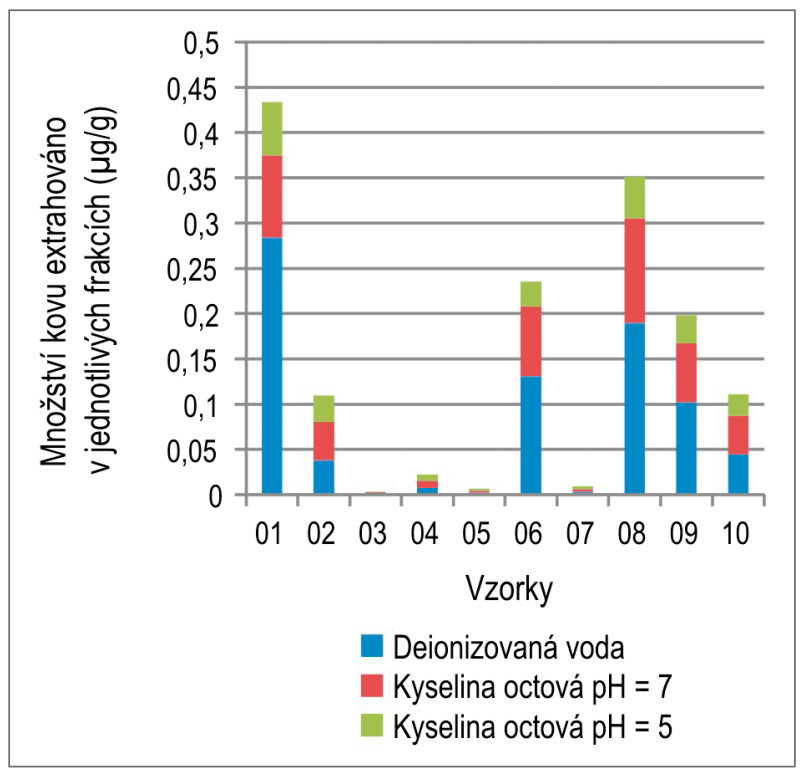

Obr. 5: Množství chromu ( $\mu \mathrm{g} / \mathrm{g})$ stanovené ve výluzích s odlišnou hodnotou $\mathrm{pH}$.

Fig. 5: The content of chromium $(\mu \mathrm{g} / \mathrm{g})$ determined in the extracts with a different $\mathrm{pH}$. 
vázané na uhličitany (obr. 5). V případě vzorku 02 se nejvíce vanadu extrahovalo ve výměnné frakci, menší množství při použití deionizované vody a nejmenší množství kovu ve frakci vázané na uhličitany.

\section{Diskuze}

Největší množství arsenu se extrahovalo slabě kyselým činidlem, a to ve vzorcích 01, 02, 08, 09 a 10. Naopak ve vzorcích $03,04,05,06$, a 07 bylo obsaženo nejvíce arsenu $\mathrm{v}$ mobilní fázi, který představuje podíl prvku nepodléhající sorpčním procesům. Lze předpokládat, že arsen v těchto vzorcích se vyskytuje jako trojvalentní, který je podle Bradla et al. (2005) rozpustnější, mobilnější, a tedy i více toxický než arzeničnany.

Pozitivní korelace se naopak projevila mezi celkovým množstvím As a $\mathrm{Ni}(\mathrm{r}=0,69)$. Nicméně obsahy As a Ni v jednotlivých typech extraktů spolu vzájemně nekorelují. Největší množství niklu bylo extrahováno ve vzorcích 01,08 , pak 09 a 10 za použití deionizované vody. Niklu bylo během extrakčních kroků stanoveno jen malé množství. Příčinou může být vazba na Fe/Mn hydroxidy (Theis, Richter 1979) rozložitelná až silnějšími kyselinami jako např. $\mathrm{HNO}_{3}$ nebo $\mathrm{HCl}$ (Bradl et al. 2005). Nikl pozitivně koreluje s chromem $(\mathrm{r}=0,79)$ a vanadem $(\mathrm{r}=0,85) \mathrm{v}$ uhličitanové frakci. Za těchto podmínek se tedy kovy chovají stejně.

Největší množství vanadu i chromu bylo extrahováno za použití deionizované vody, a to ve vzorcích 01, 06, 08, 09 a 10. Kovy se v těchto vzorcích chovaly velice podobně. Obsah vanadu byl ve vzorcích ovšem větší než obsah chromu. Na rozdíl od chromu bylo vanadu stanoveno více i po extrakci kyselým roztokem než za použití octanu s $\mathrm{pH}=7$. Pozitivní korelace se projevila u celkového množství kovů s hodnotou $\mathrm{r}=0,87$. Velmi blízké chování chromu a vanadu potvrzuje i pozitivní korelace $\mathrm{v}$ mobilní $(\mathrm{r}=0,95)$ a uhličitanové frakci $(\mathrm{r}=0,85)$. Podle Cranse et al. (1998) je vanad ve fosilních palivech přítomen $\mathrm{v}$ oxidačním stavu především jako vanadyl (IV), který je díky svému vysokému oxidačnímu stavu dobře extrahovatelný. V mobilní frakci se dá očekávat právě tato forma vanadu, která nevykazuje pro životní prostředí nebezpečí. Riziko by mohlo nastat se změnou podmínek prostředí do neutrální či bazické oblasti. Kde by mohlo dojít k oxidaci vanadylu na toxičtější vanadičnan (De Cremer 2005).

\section{Závěr}

Metodou sekvenční analýzy bylo testováno chování arsenu, chromu, vanadu a niklu v hnědém uhlí mostecké pánve v podmínkách obvyklých při manipulaci s vytěženým uhlím, které je v kontaktu s meteorickou vodou. Arsen, chrom, vanad a nikl se z poloviny vzorků hnědého uhlí uvolnili již extrakcí deionizovanou vodou. Představují tak polutanty uvolnitelné za nejběžnějších podmínek. Arsen a chrom se uvolňoval také ze všech vzorků hnědého uhlí při extrakci slabě kyselými roztoky, takže tyto prvky se mohou uvolnit působením kyselých deštů nebo výluhů $\mathrm{z}$ haldového materiálu.

\section{Poděkování}

Laboratorní část výzkumu byla podpořena infrastrukturnimi projekty centra RECETOX PřF MU (projekt č. LM2015051 a CZ.02.1.01/0.0/0.0/16_013/0001761) a institucionální podporou Př́rodovědecké fakulty MU Brno. Děkujeme také recenzentům za odbornou korekci článku. 


\section{Literatura}

Bradl, H. B. (2005). Heavy Metals in the Environment: Origin, Interaction and Remediation. - Elsevier Academic Press. 269 pp., London.

Crans, D., Amin, S, Keramidas, A. (1998). Chemistry of relevance to vanadium in the environment. - In: Vanadium in the Environment, Part I: Chemistry and Biochemistry. - John Wiley \& Sons. New York.

De Cremer, K. (2005). Speciation of Vanadium. - In: Cornelis, R. et al. (eds): Handbook of Elemental Speciation II-Species in the Environment, Food, Medicine and Occupational Health, 464-487. Great Britain. https://doi.org/10.1002/0470856009.ch2u

Dai S., Wang X., Zhao L. (2017). Mineral matter and trace elements in coal. MDPI,

Ettler, V. (2008): Aplikace loužících metod a jejich interpretace. - Moderní analytické metody v geologii. Praha.

Feng, X., Hong Y., Hong. B., Ni, J. (2000). Mobility of some potentially toxic trace elements in the coal of Guizhou, China. - Environmental Geology, 39, 3-4, 372-377.

Finkelman, R. B. (1995). Modes of occurrence of environmentally-sensitive trace elements in coal. - In: Swaine, D. J., Goodarzi, F., (eds): Environmental Aspect of Trace Elements in Coal, Energy \& Environment, vol. 2. Springer, Dordrecht. https:// doi.org/10.1007/978-94-015-8496-8_3

Fojtík, S (2018). Chemické složení uhlí bílinské delty. - MS, diplomová práce. Ústav geologických věd, Přírodovědecká fakulta Masarykovy univerzity. Brno.

Fojtík, S., Vöröš, D., Geršlová, E. (2018). Obsah stopových prvků v uhelné hmotě spodní a svrchní lávky hlavní sloje Mostecké pánve. - Geoscience Research Reports, 51, 43-45.

Sia, S.-G., Abdullah, W. H. (2011). Concentration and association of minor and trace elements in Mukah coal from Sarawak, Malaysia, with emphasis on the potentially hazardous trace elements. - International Journal of Coal Geology, 88, 179-193.

Speight, J. G. (2016). The chemistry and technology of coal, third edition. Taylor \& Francis Group, 845 pp.

Suárez-Ruiz, I., Ward, C. R. (2014). Basic Factors Controlling Coal Quality and Technological Behaviour of Coal. - In: Suárez-Ruiz, I. and Crelling J. (eds), Applied Coal Petrology: The role of petrology in coal utilization, 408 pp.

Swaine, D. J. (1990). Trace Elements in Coal. - Butterworth \& Heinemann. 292 pp.

Taylor, G. H., Teichmüller, M., Davis, A., Diessel, C. F. K., Littke, R., Robert, P. (1998): Organic Petrology. - Gebrüder Borntraeger, Berlin-Stuttgart, $704 \mathrm{pp}$.

Theis, T. L., Richter, R. O. (1979). Chemical speciation of heavy metals in power plant ash pond leachate. .Environ. - Environmental Science and Technology, 13, 2, 219-224.

Querol, X., Juan, R., Lopez-Soler, A., Fernandez-Turiel, J. L., Ruiz, C. R. (1996). Mobility of trace elements from coal and combustion wastes. - Fuel, 75, 7, 821-838. https://doi.org/10.1016/0016-2361(96)00027-0

Tessier, A., Campbell, P. G. C., Bisson, M. (1979). Sequential extraction procedure for the speciation of particulate trace metals. - Analytical Chemistry, 51, 844-851. https://doi.org/10.1021/ac50043a017

Vejahati, F., Xu, Z., Gupta, R. (2010). Trace elements in coal: Associations with coal and minerals and their behavior during coal utilization - A review. Fuel, 89, 904-911.

Vöröš, D., Geršlová, E., Nývlt, D., Geršl, M., Kuta, J. (2019). Assessment of geogenic input into Bilina stream sediments (Czech Republic). - Environmental Monitoring and assessment, 191,2, 114-125. https://doi.org/10.1016/j.coal.2018.07.005. 